\title{
Editorial for Special Issue "Radar Technology for Coastal Areas and Open Sea Monitoring"
}

\author{
Giovanni Ludeno ${ }^{1, *(1)}$ and Marco Uttieri ${ }^{2,3, *(\mathbb{D})}$ \\ 1 Institute for Electromagnetic Sensing of the Environment (IREA), National Research Council of Italy (CNR), \\ 80124 Naples, Italy \\ 2 Department of Integrative Marine Ecology, Stazione Zoologica Anton Dohrn, 80121 Naples, Italy \\ 3 CoNISMa, ULR Parthenope, Piazzale Flaminio 9, 00196 Rome, Italy \\ * Correspondence: ludeno.g@irea.cnr.it (G.L.); marco.uttieri@szn.it (M.U.)
}

Received: 19 July 2020; Accepted: 21 July 2020; Published: 25 July 2020

Keywords: remote sensing; HF radar; X-band radar; synthetic aperture radar; radar altimeter; sea surface current; significant wave height; sea state monitoring

\section{Overview}

The sea has always played a fundamental role in the social and economic development, as well as in the shaping and functioning of natural ecosystems and services. This has led to growing attention towards the sea and its behaviour by the scientific community. In order to characterise coastal and open-ocean dynamics at the proper spatial and temporal scales, over the past few years the development of marine observatories has been spurred and promoted (e.g., [1,2]). These observation infrastructures can be composed of different platforms, each providing specific information on one or more parameters (either physical, hydrological, biological or chemical), which can then be used to reconstruct the status of the system.

Within this framework, radar systems represent a useful, non-invasive technology for retrieving sea state information. The radar systems employed for the remote sensing of the ocean surface refer to three main typologies: microwave radar, microwave radiometers and high-frequency (HF, or decametric) radar [3]. In recent decades, radar oceanography has fostered the comprehension of sea surface dynamics, including the measurement of ocean currents, waves and wind, but also target detection and operational activities (e.g., oil spill monitoring, search and rescue operations). Reviews on the different types of radars and their applications are available in the literature, providing specific details and insight [4-6].

In this regard, this Special Issue (SI) on "Radar Technology for Coastal Areas and Open Sea Monitoring", published in the Journal of Marine Science and Engineering, aims at engendering a virtual forum for ocean radar researchers, where state-of-the-art methodologies and applications concerning ocean monitoring by means of radar technologies are reviewed and discussed. In particular, for this SI we invited papers considering various topics, including ocean dynamics, open sea and coastal area monitoring, sea safety and protection, signal processing, and physical-biological interactions. After a rigorous peer review process, we accepted 13 papers, which cover a wide range of topics related to sea state monitoring in both coastal areas and the open sea.

A general classification of the contributions included in the present SI may be provided on the basis of the adopted remote sensing monitoring systems. Specifically, some of the presented studies deal with analyses of data acquired from radar systems installed in coastal areas, such as HF radar [7-14] and X-band nautical radar systems $[15,16]$, while others were mounted on satellite platforms, such as Synthetic Aperture Radar (SAR) [17,18] and Radar Altimeters (RAs) [19]. An overview of the 
contributions published is provided in the following section, showing the wide range of applications and methodologies covered in the SI.

\section{Contributions}

A great proportion of the contributions included in the SI refer to HF radar applications. Since the 1970s, HF radars have increasingly demonstrated their ability to efficiently resolve surface currents and wave fields over extended coastal basins. Three lines of investigation can be identified in the presented SI papers: characterisation of surface current fields; HF-derived surface wave measurements; baseline research on signal processing and analysis.

Surface current dynamics are investigated in three papers. The contribution by [7] reports on the long-term monitoring of the Strait of Gibraltar and the associated Atlantic inflow in the Mediterranean Sea. The authors show seasonal patterns in surface structures, but also reversal episodes, unveiling relationships with atmospheric and oceanic forcings, as well as with tides. The authors in [8] provide a new application for soft-computing techniques (random forest, RF) to forecast surface current fields in Galway Bay (Ireland). In this study, HF radar-derived fields, coupled with numerical outputs, are used as inputs for the RF model. The forecasted fields show a high consistency with the HF ones, pointing at promising implementations of these techniques for long-term simulations. The surface circulation along the southwest coast of Australia is investigated by [9]. Data merged from two systems (SeaSonde and WERA) identify a seasonal signal in the Leeuwin Current, with zonal migrations and yearly variations in magnitude. The study also highlights a modest tidal contribution, and the occurrence of persistent sub-mesoscale eddies.

The majority of the HF radar literature focuses on applications to the surface current field. HF radars, however, have the potential to measure gravity waves as well, and increasing attention has been paid to this specific topic in recent years. The validation of HF-derived waves against measurements retrieved by a wave buoy and two ADCPs is the focus of the work by [10]. Radar and in situ data show a good consistency, pointing to the crucial selection of the integration time to calculate radar directional spectra. These results indicate that the inversion method used by the authors is appropriate, leading to the absence of commonly observed errors (i.e., overestimation of wave heights and noise in short-term measurements). A wave climatology for the Gulf of Naples (Italy) is built by [11] by integrating HF radar and in situ (ADCP) measurements. The patterns reconstructed by the two platforms are consistent both at seasonal and interannual scales, and reveal specificities for the different sub-basins of the study area. The work supports the use of HF radars to properly characterise coastal processes.

The acquisition and elaboration of signals is central to the functioning of any radar system, and the quality of the data retrieved by these systems is deeply dependent upon validation and inversion procedures. The accuracy of HF measurements is strongly dependent on radiation patterns, and numerous quality control $(\mathrm{QC})$ methods have been proposed in the literature. In their contribution to the SI, the authors in [12] present a new QC method for radial current velocities based on internal consistency checks, and implement an extension of the least squares direction-finding algorithm. The automation of the procedure and its application to wave measurements are proposed as next steps. A neural network is employed by [13] to invert the HF radar Doppler spectrum, and derive directional ocean spectra. Data on wave direction, peak wave direction, peak period, period energy and significant wave height outputted by the neural network are compared with measurements retrieved through a wave buoy and a pre-existing inversion method. Good correlations confirm the robustness of the method and open the way to further implementations. The author in [14] reports on the application of a listen-before-talk (LBT) operation mode to a SeaSonde system, by which a radar scans its radio environment before transmitting. The outcomes of the investigation indicate that SeaSonde radars can perform an LBT radio scan with their existing hardware and software, although the system may lose efficiency with variable radial range resolution. Recommendations are thus made to optimise the functioning of LBT in these systems. 
Remaining in the context of coastal basins, two papers related to the use of the X-band radar system for sea state and shoreline monitoring are published in the SI. The authors in [15] present an automatic modified Temporal Waterline Method (mTWM) to extract, from time stack X-band radar images, a time series of shoreline positions and intertidal foreshore slopes in a sandy, micro-tidal beach site at Hasaki Oceanographical Research Station (HORS) in Hasaki, Japan. The comparison with the survey observations demonstrates both the accuracy and efficiency, as well as the robustness, of the proposed method. Moreover, the authors believe that the proposed tool will be useful to help authorities understand coastal changes, facilitating coastal protection and sustainable development in coastal zones. Concerning sea state monitoring, the estimation of the significant wave height (Hs) from $\mathrm{X}$-band radar images is one of the most interesting and challenging tasks. The authors in [16] propose a novel and alternative strategy for estimating Hs, which allows avoiding the calibration of the wave spectrum by means of an external sensor reference during the installation of a wave radar system. The validation is performed by considering simulated wave fields generated under various sea state conditions. The encouraging results obtained from the analysis of the simulated data mean that the work provides a proof of concept. Therefore, the application of the proposed approach on real-world data and its testing at various sites is expected.

Remote sensing satellites are equipped with sensors that allow the observation of the whole globe, or an assigned part of it within a defined time period. In the context of this SI, the sensors deployed on satellite platforms are Synthetic Aperture Radar (SAR) systems and Radar Altimeters (RAs). The authors in [17] present a feasibility study to investigate the potentialities and limitations in the extraction, from SAR data, of information about the sea surface currents in the coastal area of the Gulf of Naples (South Italy) in the Mediterranean Sea. The study shows that, generally, wind plays a direct and significant role in the observed Doppler surface current. Moreover, through the availability of an oceanographic numerical model for one of the analysed cases, the authors are able to interpret the effect of the typical thermohaline circulation pattern on the Doppler anomaly. The authors in [18], instead, present a ready-to-use approach, based on the level 2 (L2) ocean product of Sentinel-1 (S1) images, for detecting cyanobacteria blooms in the Curonian Lagoon. The use of L2 S1 products improves the spatio-temporal detection of algal blooms. Moreover, this approach is easy and self-sustainable, and is able to provide observations independent of the presence of atmospheric haze or cloud cover. Finally, the authors in [19] investigate the R-effect, i.e., the Doppler shift deriving from the orbital velocity of sea wave particles, which can have an effect on the response of Delay Doppler Altimeters (DDAs). The results show that, when the wavelength of sea waves is of the same order of magnitude as the altimeter resolution, the waveform might be significantly influenced by the R-effect. This phenomenon is particularly important for the monitoring of long swells, often taking place in open oceans.

\section{Conclusions}

The broad coverage of the research topics addressed in this SI demonstrates that radar technology is an active and expanding field of investigation, and the papers published confirm the flexibility of these approaches to advance our current knowledge of coastal and open sea dynamics. The scientific community is actively engaged in these lines of investigation, and the contributions included in the present SI will herald further developments and applications in the near future.

Author Contributions: Conceptualization, G.L. and M.U.; writing—review and editing, G.L. and M.U. All authors have read and agreed to the published version of the manuscript.

Funding: This research received no external funding.

Acknowledgments: We would like to thank all contributing authors, whose interest in this collection has made it possible to realise a SI that we are confident will have an impact on the scientific community. As SI Editors, we also owe a debt of gratitude to the reviewers, who had a key role in selecting the most appropriate papers, as well as providing useful insights and comments.

Conflicts of Interest: The authors declare no conflict of interest. 


\section{References}

1. Bastos, L.; Bio, A.; Iglesias, I. The importance of marine observatories and of RAIA in particular. Front. Mar. Sci. 2016, 3, 140. [CrossRef]

2. Crise, A.; Ribera d'Alcalà, M.; Mariani, P.; Petihakis, G.; Robidart, J.; Iudicone, D.; Bachmayer, R.; Malfatti, F. A conceptual framework for developing the next generation of Marine OBservatories (MOBs) for science and society. Front. Mar. Sci. 2018, 5, 318. [CrossRef]

3. Shearman, E.D.R. Radio science and oceanography. Radio Sci. 1983, 18, 299-320. [CrossRef]

4. Paduan, J.D.; Washburn, L. High-Frequency radar observations of ocean surface currents. Ann. Rev. Mar. Sci. 2013, 5, 115-136. [CrossRef] [PubMed]

5. Huang, W.; Wu, X.; Lund, B.; El-Darymli, K. Advances in coastal HF and Microwave (S- or X-band) radars. Int. J. Antennas Propag. 2017, 2017, 3089046. [CrossRef]

6. Yang, X.; Li, X.; Nunziata, F.; Mouche, A. (Eds.) Ocean Remote Sensing with Synthetic Aperture Radar; MDPI: Basel, Switzerland, 2018; p. 352. [CrossRef]

7. Lorente, P.; Piedracoba, S.; Sotillo, M.G.; Álvarez-Fanjul, E. Long-term monitoring of the Atlantic Jet through the Strait of Gibraltar with HF radar observations. J. Mar. Sci. Eng. 2019, 7, 3. [CrossRef]

8. Ren, L.; Miao, J.; Li, Y.; Luo, X.; Li, J.; Hartnett, M. Estimation of coastal currents using a soft computing method: A case study in Galway Bay, Ireland. J. Mar. Sci. Eng. 2019, 7, 157. [CrossRef]

9. Cosoli, S.; Pattiaratchi, C.; Hetzel, Y. High-Frequency radar observations of surface circulation features along the South-Western Australian coast. J. Mar. Sci. Eng. 2020, 8, 97. [CrossRef]

10. Lopez, G.; Conley, D.C. Comparison of HF radar fields of directional wave spectra against in situ measurements at multiple locations. J. Mar. Sci. Eng. 2019, 7, 271. [CrossRef]

11. Saviano, S.; Cianelli, D.; Zambianchi, E.; Conversano, F.; Uttieri, M. An integrated reconstruction of the multiannual wave pattern in the Gulf of Naples (South-Eastern Tyrrhenian Sea, Western Mediterranean Sea). J. Mar. Sci. Eng. 2020, 8, 372. [CrossRef]

12. Lipa, B.; Barrick, D.; Whelan, C. A quality control method for broad-beam HF radar current velocity measurements. J. Mar. Sci. Eng. 2019, 7, 112. [CrossRef]

13. Hardman, R.L.; Wyatt, L.R. Inversion of HF radar Doppler spectra using a neural network. J. Mar. Sci. Eng. 2019, 7, 255. [CrossRef]

14. Cosoli, S. Implementation of the Listen-Before-Talk mode for SeaSonde High-Frequency ocean radars. J. Mar. Sci. Eng. 2020, 8, 57. [CrossRef]

15. Kumar, D.; Takewaka, S. Automatic shoreline position and intertidal foreshore slope detection from X-band radar images using modified Temporal Waterline Method with corrected wave run-up. J. Mar. Sci. Eng. 2019, 7, 45. [CrossRef]

16. Ludeno, G.; Serafino, F. Estimation of the significant wave height from marine radar images without external reference. J. Mar. Sci. Eng. 2019, 7, 432. [CrossRef]

17. Zamparelli, V.; De Santi, F.; Cucco, A.; Zecchetto, S.; De Carolis, G.; Fornaro, G. Surface currents derived from SAR Doppler processing: An analysis over the Naples coastal region in South Italy. J. Mar. Sci. Eng. 2020, 8, 203. [CrossRef]

18. DeSanti, F.; Luciani, G.; Bresciani, M.; Giardino, C.; Lovergine, F.P.; Pasquariello, G.; Vaiciute, D.; De Carolis, G. Synergistic use of Synthetic Aperture Radar and optical imagery to monitor surface accumulation of cyanobacteria in the Curonian Lagoon. J. Mar. Sci. Eng. 2019, 7, 461. [CrossRef]

19. Reale, F.; Pugliese Carratelli, E.; Di Leo, A.; Dentale, F. Wave orbital velocity effects on radar Doppler altimeter for sea monitoring. J. Mar. Sci. Eng. 2020, 8, 447. [CrossRef]

(C) 2020 by the authors. Licensee MDPI, Basel, Switzerland. This article is an open access article distributed under the terms and conditions of the Creative Commons Attribution (CC BY) license (http://creativecommons.org/licenses/by/4.0/). 